\title{
CONTRAPOR É CANSATIVO: A ERA DA PÓS-VERDADE E SUAS APLICAÇÕES NA CAMPANHA ELEITORAL DE JAIR BOLSONARO VIA WHATSAPP
}

Gabriel Lepeck ${ }^{1}$

Rafael Luiz Zen ${ }^{2}$

\begin{abstract}
Resumo
O presente artigo tem por objetivo realizar uma análise crítica do conceito de pós-verdade, pela ótica da comunicação social, utilizando como case a campanha do presidente brasileiro Jair Bolsonaro, intitulada "Brasil Acima de Tudo, Deus acima de Todos". A análise do discurso tem como base pesquisas bibliográficas e divide-se em três momentos. Primeiramente a definição da pergunta de pesquisa; que visa responder se "a pós-verdade pode explicar a crença em massa na imensidão de notícias inverídicas espalhadas no último período eleitoral brasileiro?". No segundo momento interpreta-se a teoria contemporânea da pós-verdade, na qual fatos objetivos são preteridos em relação a narrativas emocionais; para em seguida relacioná-la com as novas mídias comunicacionais, em um foco nos discursos emitidos via aplicativo WhatsApp. Após a coleta de informações de obras impressas e artigos da internet chega-se ao resultado da pesquisa, onde identificou-se a origem do termo pós-verdade e seus efeitos na atual sociedade, concluindo que ela pode apenas em partes elucidar a convicção nas mensagens não verdadeiras criadas durante a eleição presidencial. Para explicar na totalidade tal fenômeno seriam necessários estudos mais aprofundados na área do marketing político.
\end{abstract}

Palavras-chave: Pós-Verdade. Comunicação Social. Eleições. WhatsApp.

\section{OPPOSE IS TIRING: THE POST-TRUTH ERA AND ITS APPLICATIONS IN THE ELECTORAL CAMPAIGN OF JAIR BOLSONARO'S VIA WHATSAPP}

\begin{abstract}
This article aims to analyze the concept of post-truth, from the point of view of the social communication, using the case of Brazilian president Jair Bolsonaro's campaign entitled "Brazil above all, God above everyone". This analysis of speech is based on bibliographical researches and it is divided in three moments. First the definition of the research question, which aims to answer: "can the post-truth explain the mass belief in the immensity of the untrue statements spread in the last Brazilian electoral period?". In the second moment the contemporary posttruth theory is interpreted where objective facts are deprecated in relation to emotional narratives; then relates new communication media in a focus of speeches emitted via WhatsApp. After collecting information from printed works and web articles, the result of the research is arrived, it was identified the origin of the term post-truth and its effects in current society were identified, concluding that it could elucidate only in parts the conviction on the

\footnotetext{
${ }^{1}$ Centro Universitário de Brusque (UNIFEBE), Brusque - Santa Catarina - Brasil. Bacharel em Publicidade e Propaganda pelo Centro Universitário de Brusque (UNIFEBE). ORCID $<$ http://orcid.org/0000-0002-3565-3736>. E-mail: gabriellepeckgd@gmail.com.

${ }^{2}$ Centro Universitário de Brusque (UNIFEBE), Brusque - Santa Catarina - Brasil. Mestre em Processos Artísticos Contemporâneos pela Universidade do Estado de Santa Catarina (UDESC). É coordenador e professor do curso de Publicidade e Propaganda, no Centro Universitário de Brusque (UNIFEBE), além de membro docente dos
} cursos de Design Gráfico, Design de Moda e Jogos Digitais. E-mail: rafaelzen.professor@gmail.com.
\end{abstract}




\section{Linguagens - Revista de Letras, Artes e Comunicação - ISSN 1981- 9943 \\ Blumenau, v. 14, n. 1, p. 025-044, jan./abr. 2020. \\ DOI: http://dx.doi.org/10.7867/1981-9943.2020v14n1p025-044}

untrue messages created during the presidential election, to explain such a phenomenon in full, it would be required deeper studies at the political marketing field.

Keywords: Post-Truth. Social Communication. Election. WhatsApp.

\section{INTRODUÇÃO}

Em 2016, o dicionário Oxford (2016) selecionou post-truth como a palavra do ano, termo que pode ser traduzido como pós-verdade. Como revela o escritor e especialista em comunicação José Antonio Llorente (2017, p. 9), “o panorama político e social é marcado por esta conjuntura da pós-verdade, na qual o objetivo e o racional perdem peso diante do emocional". A ela é atribuído o sucesso, até então inexplicável por cientistas políticos, da campanha presidencial norte-americana de Donald Trump (2016) e o referendo para saída do Reino Unido da União Europeia (2016), conhecido como Brexit.

Nos dois eventos, instaurou-se um regime de circulação de boatos nas redes sociais, deixando os meios de comunicação desnorteados e vulneráveis, criando um ambiente propício ao surgimento de um novo espaço social caracterizado pela pós-verdade. O jornalista e pesquisador Matthew d'Ancona (2018, p. 19) cita que "entramos em uma nova fase de combate político e intelectual, em que ortodoxias e instituições democráticas estão sendo abaladas em suas bases por uma onda de populismo ameaçador. A racionalidade está ameaçada pela emoção". E engana-se quem imagina que esta é uma realidade distante, pois os rumos da política e do processo eleitoral no Brasil também podem ser explicados pela pós-verdade.

Partindo da análise geral do fenômeno para entendê-lo em dimensões nacionais, delimita-se como pergunta de pesquisa: a pós-verdade pode explicar a crença em massa na imensidão de notícias inverídicas espalhadas via aplicativo WhatsApp no último período eleitoral brasileiro? A reposta será pensada através do estudo do objeto de pesquisa, traçado como a análise do case da campanha de Jair Bolsonaro na eleição presidencial brasileira (2018), intitulada "Brasil Acima de Tudo, Deus acima de Todos".

Orientando o estudo, são estipulados os objetivos que organizam o caminho de informações, a fim de responder na totalidade a pergunta central. Neste estudo o objetivo geral é tido como interpretar o contexto e o conceito de pós-verdade, relacionando-o com os discursos emitidos via WhatsApp ligados à campanha "Brasil Acima de Tudo, Deus acima de Todos" do presidente supracitado.

Os objetivos específicos da pesquisa foram definidos como: teorizar o que é pós-verdade na contemporaneidade, tanto em escala global quanto nacional; correlacionar o uso da internet 


\section{Linguagens - Revista de Letras, Artes e Comunicação - ISSN 1981- 9943 \\ Blumenau, v. 14, n. 1, p. 025-044, jan./abr. 2020. \\ DOI: http://dx.doi.org/10.7867/1981-9943.2020v14n1p025-044}

com o fortalecimento dos discursos pós-verdadeiros; provar a função do WhatsApp como facilitador de propagação de informação e apresentar o uso do aplicativo na campanha Bolsonaro; e, por fim, verificar a utilização da pós-verdade como ferramenta de discurso e marketing político durante a campanha aqui citada.

Para a boa realização deste artigo científico, estipula-se desde seu início uma metodologia a ser aplicada. Como citam os doutores Jorge Duarte e Antônio Barros (2011, p. 17), “o conhecimento científico provém do aproveitamento, através das generalizações e interpretações teóricas, das leis e regularidades descobertas, tanto de fenômenos naturais quanto sociais". Portanto, cabe a seleção de um método para teorizar e entender os acontecimentos sociais a serem estudados.

A opção aqui é por uma coleta de dados bibliográficos. Segundo a pesquisadora Ida Regina C. Stumpf (2011, p. 51), este método "é um conjunto de procedimentos que visa identificar informações bibliográficas pertinentes ao tema estudado", neste caso, selecionando obras que falem da teoria da pós-verdade. Porém, devido ao período atual da temática, utilizase também a internet como fonte de informação, selecionando artigos científicos e de opinião disponibilizados na web.

Por fim, é realizado um estudo de caso, por vez a campanha presidencial "Brasil Acima de Tudo, Deus Acima de Todos” de Jair Bolsonaro. Como revela a pesquisadora Marcia Yukiko Matsuuchi Duarte (2011, p. 215), “o estudo de caso é utilizado extensivamente em pesquisa nas ciências sociais e teses, por ser uma boa maneira de introduzir o pesquisador iniciante nas técnicas de pesquisa", no qual se investiga um fenômeno contemporâneo ligado ao objeto de pesquisa.

Em suma, este artigo propõe a união de três temáticas atuais e de imensa relevância social: discursos políticos, fortalecimento das redes sociais e a pós-verdade. O encontro do estudo de caso da campanha presidencial brasileira eleita, na qual utilizou-se reconhecidamente o WhatsApp para o fortalecimento dos discursos políticos e ideológicos, é um ambiente rico para análises críticas, que relacionadas as novas narrativas da verdade podem ser suporte para compreender o atual momento da sociedade e vislumbrar os próximos caminhos sociais.

\section{AS NARRATIVAS DA VERDADE}

Entender e classificar o que é a verdade foi, e continua sendo, o objetivo de diversos pensadores nas mais distintas sociedades, como nas antigas gregas e romanas, na Idade Média, 


\section{Linguagens - Revista de Letras, Artes e Comunicação - ISSN 1981- 9943 \\ Blumenau, v. 14, n. 1, p. 025-044, jan./abr. 2020. \\ DOI: http://dx.doi.org/10.7867/1981-9943.2020v14n1p025-044}

moderna e contemporânea. A temática sempre envolveu debates, como em seus primórdios onde Platão e os Sofistas - professores itinerantes da antiga Grécia, que ensinavam a arte da retórica - opunham-se sobre o poder da argumentação e a existência de uma verdade única.

Em um salto histórico remete-se à verdade da era medieval, caracterizada por crenças seculares apoiadas na religião; ou para advento do positivismo - início do século XIX - do filósofo e sociólogo francês Auguste Comte e as verdades fundamentadas apenas naquilo que pode ser comprovado cientificamente.

No período pós-moderno, pensadores como Michael Focault, Jean-Francois Lyotard, Jacques Derrida, Jean Baudrillard e Richard Rorty se destacaram estudando a maleabilidade da sociedade, identificando a necessidade de reconhecer a pluralidade e encorajando as múltiplas vozes a questionar os sistemas vigentes. Foucault, em 1988, escreve a obra Verdade e Poder. Nela ele define o que é a verdade, associando o termo com a luta de poderes midiáticos, políticos e econômicos. Conforme Bezerra, Capurro e Scheneider (2017, p. 374) debatem a ótica foucaultiana afirmando:

\footnotetext{
Aproximamo-nos da leitura de Foucault (1996) sobre o que chama de "regimes de verdade", entendidos como conjuntos ordenados de proposições, instituições e disciplinas que organizam e controlam os discursos e impõem-se como estratégias de manutenção do poder, por meio de uma política universal da verdade submetida às disciplinas e sanções normalizadoras. Em tais regimes, práticas e técnicas são instituídas com o objetivo de promover uma determinada percepção sobre a verdade e, assim, planificar a conduta humana, submetendo os indivíduos às instituições e aos procedimentos normativos do poder.
}

Nesta leitura de Foucault chegamos ao termo narrativas da verdade, na qual o autor relata a presença de regimes normativos, nos quais as verdades são criadas e controladas com o intuito de manter o poder vigente e predeterminar as ações sociais dentro de padrões normalizadores. Constata-se que a verdade também é mutável, visto que cada sociedade possui suas particularidades e características que sobressaem, e dentro do contexto social vários outros grupos identitários criam a sua versão da realidade, tornando distinta a concepção do que é verdadeiro. É neste cenário cíclico que se encontra a verdade da idade contemporânea, onde vive-se a era da pós-verdade.

A pós-verdade é classificada pelo dicionário da Universidade de Oxford (2016, s/p), como "circunstâncias nas quais fatos objetivos têm menos influência em moldar a opinião pública do que apelos à emoção e a crenças pessoais". Em artigo sobre os Regimes de Verdade e Poder, Bezerra, Capurro e Schneider (2017, p. 373) instigam a reflexão sugerindo que ao trocar o termo "crenças pessoais por crenças religiosas, poderíamos concluir tratar-se de uma 


\section{Linguagens - Revista de Letras, Artes e Comunicação - ISSN 1981- 9943 \\ Blumenau, v. 14, n. 1, p. 025-044, jan./abr. 2020. \\ DOI: http://dx.doi.org/10.7867/1981-9943.2020v14n1p025-044}

caracterização da ideia do que seria verdadeiro no período medieval". Porém, concordar com esta visão pode ser simplório demais, mesmo que as crenças pessoais e de apelo emocional se assemelhem às religiosas, por ambas criarem novas certezas, a atualidade difere-se da Idade Média.

O que acontece agora não é uma superação das verdades positivistas, as inspiradas na teoria de Comte, onde algo passava a ser crível apenas após comprovações metódicas baseadas na ciência. Hoje, existe uma desconfiança proposital no positivismo. O assentamento da pósverdade se solidifica nos discursos políticos e impulsionados pelas novas ferramentas de comunicação, como cita Matthew d'Ancona (2018, p. 17) “o que acontece de novo agora não é desonestidade e as falsidades dos políticos, mas a resposta do público a isso. A indignação dá lugar à indiferença e, finalmente, à conivência”. Ou seja, a verdade não deixou de existir, porém passa por um momento onde as narrativas morais e de bagagem cultural são mais fortes, já que os fatos de caráter afetivos são mais aceitos, dados e informações não transparecem emoção e são entendidos como fora da realidade e menos cativantes.

Mesmo não sendo objetivo deste artigo criar uma discussão epistemológica do que seria verdadeiro, tais considerações são de grande importância. Elas ajudam a entender que a pósverdade não é um mero modismo, mas sim um novo regime de concepção para termo verdade, visto que ela é um conjunto de ideais utilizados por grupos sociais para se identificar e organizar o seu espaço, moldando seus discursos ao entorno do que seria verídico frente as temáticas da época.

O interessante é compreender como a nova narrativa surgiu, entendendo quais fatores impulsionaram seu aparecimento e identificar suas consequências. Pontua-se, que como já identificado o campo do que tange a verdade é amplo. Portanto, para melhor aprofundamento será focado em determinadas temáticas. Entender as raízes históricas deste novo fenômeno, o como ele se fortaleceu nos últimos cinco anos e em quais discursos está mais presente é o intuito.

\subsection{A ERA DA PÓS-VERDADE: CONTRAPOR É CANSATIVO}

A fama mundial do termo pós-verdade surgiu após o mesmo ser nomeado a palavra do ano em 2016. Essa escolha muito deve-se as análises da eleição para presidente dos Estados Unidos (2016), da qual Donald Trump saiu vitorioso; além da votação popular do Brexit (2016), onde os habitantes do Reino Unido votariam para a saída do país da União Europeia. Em ambas 


\section{Linguagens - Revista de Letras, Artes e Comunicação - ISSN 1981- 9943 \\ Blumenau, v. 14, n. 1, p. 025-044, jan./abr. 2020. \\ DOI: http://dx.doi.org/10.7867/1981-9943.2020v14n1p025-044}

as ocasiões especialistas da área de comunicação e política apontaram a pós-verdade como influenciadora nos resultados dos pleitos.

Porém, são duas situações datadas antes do século XXI que contextualizam as raízes históricas da terminologia, comprovando que essa propensão à desvalorização de fatos comprovados por dados, em favor daqueles com apelos sentimentais, pode não ser algo novo, mas é atual.

Primeiramente, recorre-se aos pensadores pós-modernos e sua forma de entender a sociedade, sobretudo pela ótica de Foucault. E, em um segundo momento, identifica-se o surgimento do termo pós-verdade, utilizado pela primeira vez em um artigo da Revista The Nation (1992), escrito pelo jornalista norte-americano Steve Tesich.

Vertente de pensamento que marcou o século XX, o pós-modernismo teve seu início na França quando grupos estudantis protestaram contra o governo local, em um movimento conhecido como "maio de 1968". Tal manifestação levou a uma época de renovação dos valores sociais então vigentes. Na obra Microfísica do Poder $(2005$, p. 6), Foucault relata que antes da revolta "ninguém (tanto da direita como da esquerda) se preocupava com a questão de como o poder se exercia”. Constatando a ebulição das mais distintas vozes sociais, o sociólogo passou a estudar o poder e a construção destas narrativas discursivas.

Ao se observar os pedidos contemporâneos por inclusão e liberdade, tanto de expressão quanto de pensamento, ratifica-se a influência dessa escola de pensamento nos dias de hoje. Além destas circunstâncias, o pós-modernismo ajuda a delimitar como as verdades são socialmente definidas, como esclarece Matthew d'Ancona (2018, p. 85):

\footnotetext{
Os principais pensadores associados a essa escola, ao questionar a própria noção de realidade objetiva, desgastaram muito a noção de verdade. Seu terreno natural era a ironia, a superfície, o distanciamento e a fragmentação. Preferiam entender a linguagem e a cultura como "constructos sociais"; ou seja, fenômenos políticos que refletiam a distribuição de poder através de classe, raça, gênero, em vez de ideais abstratos da filosofia clássica.
}

Para uma melhor leitura, os constructos sociais citados são somados à moral e à verdade, já que ambas são narrativas sociais, pois tratam de criações mentais. Por meio desse exercício comparativo que se torna possível cunhar a terminologia pós-verdade, que rompe com a busca incessante da razão, um anseio clássico e iluminista. Agora, os fatos verdadeiros tomam uma conjuntura relativista, em um cenário de hiper-realidade, onde diversas narrativas podem ser interligadas, mesmo que de forma manipulada, hiperbólica e até desconexa. 


\section{Linguagens - Revista de Letras, Artes e Comunicação - ISSN 1981- 9943 \\ Blumenau, v. 14, n. 1, p. 025-044, jan./abr. 2020. \\ DOI: http://dx.doi.org/10.7867/1981-9943.2020v14n1p025-044}

Chega-se assim à ideia de que a pós-verdade não é algo falso, tampouco uma verdade como na visão moderna do termo; mas sim, onde as mentiras são cristalizadas e o que é verídico transforma-se em banal, em suma os enganos se tornaram materializados, sendo concretizados; já a verdade adquire forma subjetiva.

Nesta nova perspectiva, mentir não é assustador e politicamente incorreto, pois o sujeito cria e manipula narrativas através de sua bagagem cultural, desenvolvendo um discurso que engana e convence a si próprio. "As verdades tornam-se banais, pois não se busca investigar fatos; se uma falácia é proferida dentro do grupo social a qual o sujeito pertence, ela poderá tornar-se crível" (LEPECK, ZEN, 2019, s/p), pois permanecer na conformidade das bolhas sociais parece mais oportuno. Contrapor tornou-se cansativo.

Exemplifica-se de forma prática o perecimento do pós-modernismo, resultando na pósverdade, quando se analisa que a comprovação de acontecimentos não é mais uma prioridade. Nos dias atuais, é comum a utilização do aplicativo WhatsApp para transmitir conteúdos pósverdadeiros, que acusam meios e veículos da mídia tradicional de tendenciosos e defensores de certas questões de maneira hegemônica. Essa forma de discurso sintetiza a união entre a realidade e a imaginação, uma vez que a teoria conspiratória será aceita por certos sujeitos, que criarão narrativas históricas e de bagagem emocional para concordar em seu favor.

Após um panorama sociológico, é pertinente identificar a criação do termo pós-verdade. Remete-se então ao ano de 1992, quando o jornalista Steve Tesich expõe a crise da verdade nos Estados Unidos. O país enfrentava casos de corrupção, que culminaram na renúncia do presidente Richard Nixon e denúncias a chefes da CIA que consentiram o envio clandestino de armamento para o Irã. Tesich (1992) escreveu sobre esses acontecimentos e seus reflexos sociais em artigo para a revista The Nation, visto na obra Matthew d'Ancona (2018, p. 21):

\footnotetext{
Estamos rapidamente nos tornando protótipos de um povo em que os monstros totalitários podem babar em seus sonhos. Todos os ditadores até agora tiveram que trabalhar duro para suprir a verdade. Por meio de nossas ações, estamos dizendo que isso não é mais necessário, que adquirimos um mecanismo espiritual capaz de despojar a verdade de qualquer significado. De uma maneira bastante radical, como povo livre, decidimos livremente que queremos viver em um mundo da pós-verdade.
}

O escritor não aborda fatos que caracterizam a temática pós-verdadeira na atualidade, como os aspectos emocionais, mas já delimita uma sociedade com os valores do que é verdadeiro desgastado, procurando explicar a realidade por meio de construções intelectuais próprias. Uma releitura dos escritos de Tesich ainda, com o contexto de desilusão política, pode ser um aporte ao estudo de caso do cenário político brasileiro dos últimos cinco anos. 


\section{Linguagens - Revista de Letras, Artes e Comunicação - ISSN 1981- 9943 \\ Blumenau, v. 14, n. 1, p. 025-044, jan./abr. 2020. \\ DOI: http://dx.doi.org/10.7867/1981-9943.2020v14n1p025-044}

O Brasil vive uma época conturbada em questões sociais e políticas, muito disso devese as investigações que levaram ao impeachment de Dilma Rousseff (2016) e a prisão de expresidentes eleitos, Luiz Inácio Lula da Silva (2018) e Michel Temer (2019). Essas figuras eram os líderes máximos da nação, que após estarem envoltos em casos de corrupção perderam a confiança da população, que passou a clamar por renovações e ser representada por pessoas não contaminadas pela política. Porém, como Steve Tesich (1992) descreve, esse desejo do povo por liberdade e procura de novas alternativas, muitas vezes não é bem arquitetado, abrindo espaço para figuras contrárias ao processo democrático surgirem, apoiadas em discursos que utilizam fatos alternativos.

Em artigo de opinião publicado no blog "Caos Filosófico" (2019, s/p) os pesquisadores Gabriel Lepeck e Rafael Zen, reforçam a ligação entre tal cenário e a pós-verdade:

$\mathrm{Na}$ fragilidade das democracias reside um grande condutor dos discursos pósverdadeiros. A desconfiança na figura dos líderes leva também a dúvidas perante especialistas; não é mais suficiente analisar os fatos com números e provas (realidade objetiva), é preciso cativar as pessoas, falando as verdades que elas querem ouvir (realidade subjetiva).

Um paralelo entre os atuais fenômenos sociais com o pós-modernismo e a origem do termo pós-verdade pode ser traçado, para identificar e compreender a frequência e o poder em que estes discursos são vistos agora; nesta questão que reside a comprovação que o hoje é distinto do século XX. O que cabe é refletir como a pós-verdade ganhou representatividade e impacto.

Neste momento que a esfera política e as eleições recebem destaque. Durante a campanha presidencial dos Estados Unidos em 2008, o candidato Barack Obama de forma inédita passou a utilizar as plataformas digitais para divulgação eleitoral, porém apenas em 2016 com Donald Trump que tal artifício passa a ter caráter estratégico. A campanha de Trump, intitulada Make America Great Again - Torne a América Grande Novamente, foi arquitetada pelo estrategista-chefe Steve Bannon, que usou as redes sociais para encontrar certas bolhas, criando discursos específicos para cada um desses grupos fechados e formados por indivíduos com ideias semelhantes. As falas do presidenciável eram aceitas e causavam impacto, pois traziam sobretudo anseios emocionais e não racionais, como os ataques contra os latinos e o fechamento da fronteira com o México, direcionados aos patriotas.

Tratando-se de um fenômeno global, a pós-verdade não seria restrita apenas ao Brexit, ou como visto no exemplo acima as eleições norte-americanas. Em 2018, os fatos alternativos utilizados na política chegaram no Brasil, representados na campanha "Brasil Acima de Tudo, 


\section{Linguagens - Revista de Letras, Artes e Comunicação - ISSN 1981- 9943 \\ Blumenau, v. 14, n. 1, p. 025-044, jan./abr. 2020. \\ DOI: http://dx.doi.org/10.7867/1981-9943.2020v14n1p025-044}

Deus Acima de Todos", de Jair Bolsonaro. Os presidenciáveis nutrem uma semelhança em suas falas e comportamento perante a imprensa, que rendeu ao brasileiro a alcunha da mídia internacional de "Trump do Trópicos", mas a similaridade entre ambos é apresentada também nas estratégias eleitorais. Bolsonaro moldou seus discursos, de forma emotiva, para bolhas sociais pré-estabelecidas, dialogando com a verdade desses grupos.

O sucesso da campanha "Brasil Acima de Tudo, Deus Acima de Todos" no pleito de 2018, avaliza a teoria de Bosco (2017), onde a internet é delimitada como o novo espaço público brasileiro. Nas plataformas digitais as lutas identitárias são avolumadas e há uma fragmentação social, ocasionando uma tensão entre círculos sociais diferentes. Como o autor pontua, "unidos todos por um ideal qualquer, as pessoas agem como um enxame de abelhas atacando moralmente um indivíduo identificado contra esse ideal” (BOSCO, 2017, p. 16), a proporção deste enxame aumenta quando se trata de eleitores e temáticas políticas, onde o conflito de opostos compõe o cenário estrutural.

Portanto, contextualizar como a internet possibilitou os debates comunitários e políticos induz a identificar a era da pós-verdade como atual e de grande interferência nas temáticas da comunicação social. As redes sociais e demais aplicativos, como Facebook, Twitter e WhatsApp, constituíram um cenário diferente dos demais já conhecidos, na qual a participação e a interação dos sujeitos possibilitam o surgimento das mais distintas narrativas, sejam elas verídicas ou não, mas com o poder de conectar-se ao lado emotivo das pessoas e então compartilhadas sem serem legitimadas pela razão. Comprova-se a importância de identificar o uso de tais plataformas da web, nas campanhas Trump, Brexit e Bolsonaro, para posteriormente atestar se elas tiveram influência nos resultados.

\section{O MUNDO DIGITAL E A FACILITAÇÃO DA PROPAGAÇÃO DE DISCURSOS}

Como a professora da Universidade Columbia e PHD em Ciências da Informação, Alexis Wichowski (2017, s/p), cita em entrevista ao canal Um Brasil, "um dos desafios da nossa era é que a tecnologia e nossos hábitos de consumo de informação estão mudando rapidamente. Mas ainda nós não entendemos o que isso está fazendo conosco". É nesta incerteza que o espaço dos méritos da internet mescla-se com os malefícios, onde sabidamente, ou não, pessoas desvalorizam a verdade.

A desvalorização ocorre principalmente nas redes sociais, que conforme o teórico Eli Pariser (2012, p. 14), “deixam os internautas presos em bolhas invisíveis, o que faz com que 


\section{Linguagens - Revista de Letras, Artes e Comunicação - ISSN 1981- 9943 \\ Blumenau, v. 14, n. 1, p. 025-044, jan./abr. 2020. \\ DOI: http://dx.doi.org/10.7867/1981-9943.2020v14n1p025-044}

essas empresas internacionais mostrem somente aquilo que acreditam que o internauta anseia visualizar". Este fenômeno nomeado de filtro bolha consequentemente leva a formação das bolhas sociais, que são grupos formados por pessoas cujas afinidades fazem com que seja moldado um cenário onde se atenua a propagação de opiniões semelhantes - muitas vezes facilitando a predisposição ao repúdio do que moralmente, eticamente ou politicamente difere das verdades do grupo.

Bosco (2017, p. 21) classifica essa como umas das grandes características do novo espaço público, "que tem um núcleo originador descentrado e fragmentado", o que difere da grande mídia que dispõe a mesma propagação a todos os espectadores. Nessa ótica, "as redes sociais mobilizam nichos com informações que variam de acordo com os segmentos" (BOSCO 2017, p. 22), ignorando o que se passa nas demais bolhas ou até desqualificando possíveis debates por serem propostos por pessoas de outro grupo.

Este fator é cunhado por Bosco (2017, p. 30) como bonding, que significa a ação de fortalecer laços, por criar laços grupais, estabelecendo uma coesão radicalmente baseada em fatores excludentes e de forte lealdade ao grupo. Mas esses vínculos sociais podem ser expandidos de forma não intencional pelos indivíduos. Isso ocorre quando se identifica a presença de algoritmos nas redes sociais, que determinam o quê, como e quando as informações chegarão aos usuários. Este fato retroalimenta as bolhas sociais por reforçar fatos já vistos dentro do grupo pertencente e representam grande importância para a comunicação social contemporânea, sendo o objeto de estudo do pesquisador Tarleton Gillespie da Microsoft Research New England, que em seu artigo “A Relevância dos Algoritmos”, cita:

\footnotetext{
Os algoritmos são projetados para calcular o que "está em alta", o que "é tendência" ou o que é "mais discutido", nos oferecem uma camada superficial das conversas aparentemente sem fim que estão disponíveis (...). São hoje a lógica central que controla o fluxo de informações. (GILLESPIE, 2018, p. 97)
}

O fluxo de informação é organizado por meio dos dados de acessos dos usuários, que involuntariamente entregam suas bases comportamentais. Isso se tornou uma das grandes mazelas da internet, permitindo o caso Cambridge Analytica, empresa privada que buscava e analisava dados pessoais no Facebook, porém sem permissão. Esses elementos eram traduzidos em perfis de eleitores e foram encomendadas pelo comitê da campanha de Donald Trump (2016).

Tal caso teve influência nos debates políticos e sociais, onde buscava-se entender o limite e as ferramentas éticas para a persuasão eleitoral. Neste contexto, o Brasil sancionou, em 


\section{Linguagens - Revista de Letras, Artes e Comunicação - ISSN 1981- 9943 \\ Blumenau, v. 14, n. 1, p. 025-044, jan./abr. 2020. \\ DOI: http://dx.doi.org/10.7867/1981-9943.2020v14n1p025-044}

outubro de 2017, a lei 13.488 que impunha limites nas propagandas políticas nas redes sociais. Por exemplo, apenas seriam aceitos anúncios vinculados aos Cadastros Nacionais de Pessoas Jurídicas (CNPJs) da própria campanha. Já ao Facebook, caberia sinalizar que esta propaganda tinha cunho político e quais afinidades levaram esse anúncio a chegar à pessoa.

Com estas barreiras legais, uma nova rede social destinada à comunicação ganhou poder como ferramenta eleitoral: o WhatsApp. Trata-se de um aplicativo de mensagens instantâneas e criptografadas, o que permite que elas não sejam vistas por terceiros. Em entrevista ao canal do YouTube "Rede Mídia", a professora da UniBH Lorena Tárcia (2017, s/p) classifica que “quando o problema está no Facebook ou Google, ainda está fácil, pode se mudar o algoritmo e averiguar. O grande desafio está em ferramentas fechadas como o WhatsApp, onde não se sabe o que está circulando”. A fiscalização para levantar a veracidade das informações compete apenas ao próprio sujeito.

Este ambiente extremamente fechado, com capacidade de potencializar as bolhas sociais e o fenômeno bonding por permitir a criação de grupos segmentados para a troca de mensagens na qual não é destinada a discussão, mas apenas o envio de conteúdos similares e ligados ao mesmo ponto de vista, foi explorado pelos políticos. Uma grande rede de conteúdos pósverdadeiros foi espalhada no WhatsApp no último período eleitoral brasileiro, portanto entender as dimensões desta ferramenta é essencial para explicar muitos aspectos do novo espaço público com foco o contexto político.

\subsection{O APLICATIVO DE MENSAGENS WHATSAPP}

Segundo pesquisa do IBOPE (2017), o WhatsApp é a rede social mais utilizada no Brasil, onde o aplicativo é encontrado em 91\% dos smartphones da população. Tal número ajuda a contextualizar o impacto da ferramenta no país, que ganhou uso político no pleito de 2014, mas em 2018 tornou-se um dos pilares estratégicos eleitorais.

A socialização dentro da ferramenta segue um padrão de nichos, no qual são privilegiadas interações com pessoas pré-determinadas e que formam as bolhas sociais. Neste contexto o viés pós-verdadeiro torna-se prática, pois um fato verídico é preterido por uma mensagem que traga narrativas convenientes, citando informações não verdadeiras, mas que a carga histórica julga ser crível e induz a veracidade.

Além do fator citado acima, o WhatsApp aproxima-se da pós-verdade também pela capacidade de potencializar vozes emocionais em detrimento da razão. Tal visão é endossada 


\section{Linguagens - Revista de Letras, Artes e Comunicação - ISSN 1981- 9943 \\ Blumenau, v. 14, n. 1, p. 025-044, jan./abr. 2020. \\ DOI: http://dx.doi.org/10.7867/1981-9943.2020v14n1p025-044}

por Daniel Braga (2017, s/p), publicitário e coordenador das redes sociais do político e atual governador de São Paulo João Dória, que cita que as mensagens ali compartilhadas são "menos profundas, com menos pensamento, instantâneas" além de ser "uma ferramenta subterrânea, onde as pessoas se sentem menos expostas para compartilhar algo que ficaria gravado no perfil de outras redes sociais" (BRAGA, 2017, s/p). Tais fatores seriam alarmantes para quaisquer condições sociais, já que permeiam o anonimato e a ausência de lei controladora, mas aplicados ao cenário político é ainda mais impactante.

Uma das únicas normativas existentes não está associada aos órgãos legais, mas sim aos termos de uso do próprio WhatsApp que proíbe a criação de mensagens automáticas, barrando a presença de robôs nos envios. Porém, nota-se nas estratégias políticas a utilização de empresas que vendem disparos massivos para uma base de dados advinda de fins indevidos, sem a consciência do usuário. Esta ação busca emancipar as mensagens e conseguir em seguida compartilhamentos não automatizados.

Os líderes da campanha "Brasil Acima de Tudo, Deus Acima de Todos" se depararam com um mínimo espaço de propaganda na grande mídia e entenderam as singularidades citadas deste novo espaço social, aproveitando extensamente a internet nas estratégias de marketing. Ela se associou a um grupo criado com os aspectos de bonding - a nova direita brasileira - que tinha fortes laços sociopolíticos e buscavam um representante para instaurar sua narrativa de verdade. Utilizaram-se de grupos de articulação no WhatsApp para reforçar contos pósverdadeiros, como o "Não Houve Ditadura no Brasil”, "Conteúdos Eróticos São Distribuídos em Escolas" e o "Kit Gay".

Figura 01. Fatos inverídicos proferidos por Jair Bolsonaro durante processo eleitoral.

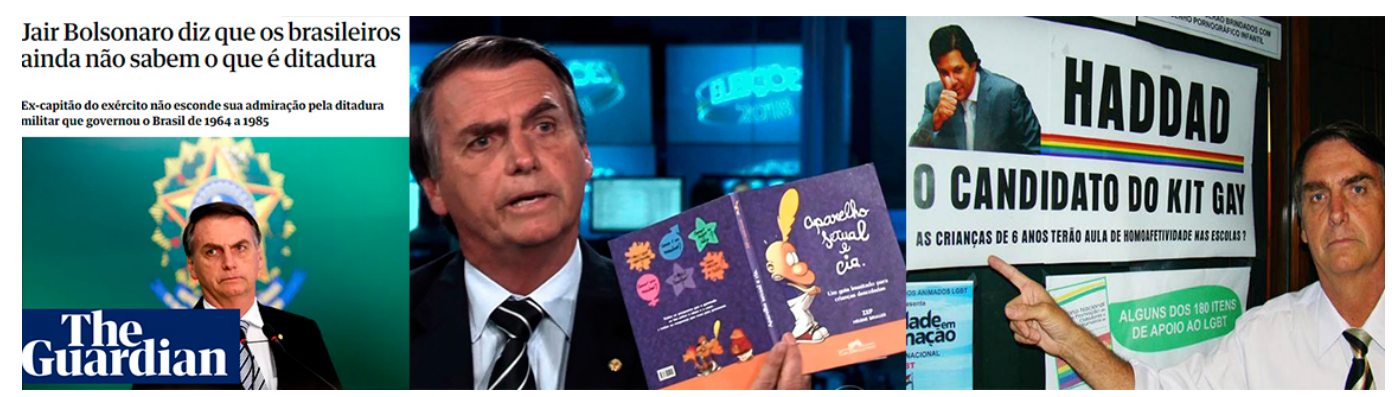

Fonte: Colagem digital criada pelo autor do artigo com imagens do portal de buscas Google (2019).

Todos estes acontecimentos foram historicamente, ou pela ausência de fatos, comprovados como inverídicos, mas uma vez que emancipados via mensagens de aplicativo ganharam proporção e credibilidade. Isso acontece pois eles dialogam com os discursos da 


\section{Linguagens - Revista de Letras, Artes e Comunicação - ISSN 1981- 9943 \\ Blumenau, v. 14, n. 1, p. 025-044, jan./abr. 2020. \\ DOI: http://dx.doi.org/10.7867/1981-9943.2020v14n1p025-044}

bolha social, criando conspirações que são transmitidas por pessoas as quais o sujeito nutre confiança, como amigos e familiares, endossando a narrativa fantasiosa.

Figura 2. Fatos inverídicos proferidos por Jair Bolsonaro durante processo eleitoral
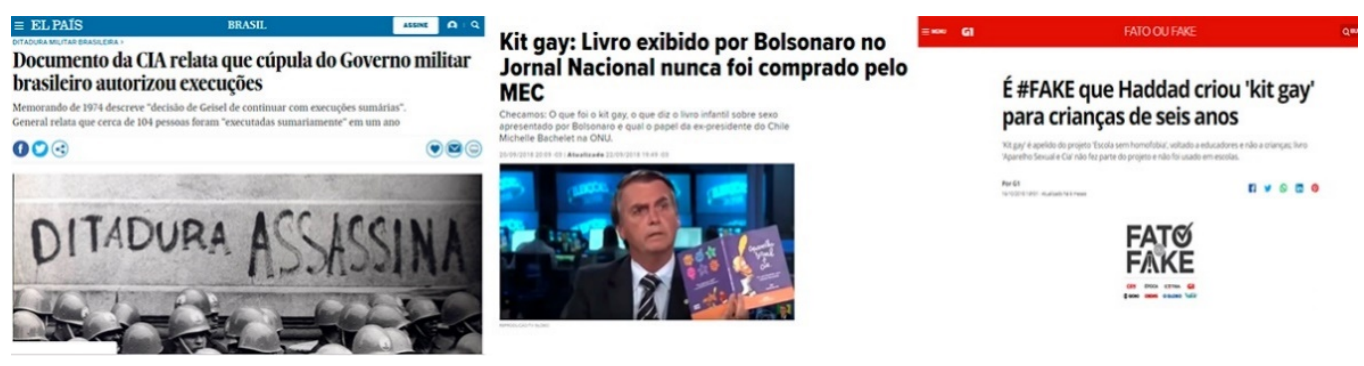

Fonte: Colagem digital criada pelo autor do artigo com imagens do portal de buscas Google (2019).

Como pode ser visto, muitos veículos desenvolveram um expediente chamado de FactChecking (em português: verificando fatos), responsável por averiguar as inúmeras notícias criadas nas plataformas digitais e não condizentes com a realidade dos fatos. O Projeto Comprova e a Agência Lupa, são exemplos dessas iniciativas que ajudam a informar sobre a Ditadura Militar Brasileira, a não distribuição de livros eróticos pelo MEC e que o candidato Fernando Haddad não criou o Kit Gay. Porém, essas verdades não eram aceitas pelos sujeitos, que foram transformados em defensores da marca Bolsonaro, visto que o presidenciável dialogava com as verdades simbólicas dos indivíduos; já as narrativas informativas não agradavam, pois opunham e tiravam do conformismo da bolha social.

Os aspectos dessa estratégia podem ser analisados de forma mais aprofundada, com o intuito de entender como que durante a campanha "Brasil Acima de Tudo, Deus Acima de Todos", vários boatos surgiram no WhatsApp e porque eles foram críveis para tantas pessoas, verificando o êxito estratégico na utilização como marketing político das multiplataformas.

\section{A UTILIZAÇÃO DE MULTIPLATAFORMAS NA CAMPANHA "BRASIL ACIMA DE TUDO, DEUS ACIMA DE TODOS"}

Antes de entender o bom uso das plataformas digitais como ferramentas de marketing durante a campanha "Brasil Acima de Tudo, Deus Acima de Todos" é necessário compreender que elas não foram selecionadas apenas por serem compreendidas como um novo espaço cultural e ambiente rico para a propagação do discurso proposto. A utilização da internet e do novo espaço social brasileiro - as redes sociais - foi, acima de tudo, uma necessidade. 


\section{Linguagens - Revista de Letras, Artes e Comunicação - ISSN 1981- 9943 \\ Blumenau, v. 14, n. 1, p. 025-044, jan./abr. 2020. \\ DOI: http://dx.doi.org/10.7867/1981-9943.2020v14n1p025-044}

Em normativas de 2018 do Tribunal Superior Eleitoral (TSE), ficou determinado o tempo que cada presidenciável teria de espaço publicitário na mídia de massa, rádio e televisão. Esta divisão seguiu o padrão correspondente à bancada de cada partido na Câmara de Deputados. Assim, o maior tempo foi concedido ao candidato Geraldo Alckmin (Partido da Social Democracia Brasileira - PSDB) com 5 minutos e 32 segundos diários e 434 inserções totais. Já Jair Bolsonaro (Partido Social Liberal - PSL) teria o tempo diminuto de 8 segundos e 11 inserções. Tal normativa ajudou a construir uma narrativa de Bolsonaro ser uma mudança perante a democracia vigente, já que não era privilegiado pelo sistema implantado.

Vislumbrando tal cenário desfavorável de exposição midiática, a campanha "Brasil Acima de Tudo, Deus Acima de Todos" criou um planejamento de comunicação focado no universo digital, utilizando-se de multiplataformas como páginas no Facebook, Twitter e disparos em massa via WhatsApp. No cerne da mesma estratégia estava o descaso à mídia tradicional, quando o candidato não comparecia a debates e frequentemente taxava os meios jornalísticos como criadores de notícias falsas.

A utilização das redes sociais de maneira extensiva e a desvalorização da outrora mídia tradicional pode ser entendida como materializações da cultura da convergência. Tal termo é cunhado pelo pesquisador em Ciências Humanas e Mídia, Henry Jenkins (2009, p. 29), que descreve que hoje "é necessário compreender o mundo atual sob uma ótica convergente, na qual as velhas e as novas mídias parecem entrar em total rota de colisão”. Nesse cenário, as mídias atuais ganham espaço por serem participativas e interativas, onde as narrativas não são apenas lidas pelo sujeito, mas também criadas. É nessa participação do sujeito que a ênfase da teoria de Jenkins se encontra, pois como o mesmo cita:

\footnotetext{
A convergência não ocorre por meio dos aparelhos. A convergência ocorre dentro dos cérebros dos sujeitos e em suas interações sociais com os outros. Cada um constrói a própria mitologia pessoal, a partir de pedaços e fragmentos de informações extraídos do fluxo midiático e transformados em recursos, através dos quais compreendemos o cotidiano (JENKINS, 2009, p. 30).
}

Porém, a contemporaneidade é construída cada vez mais por bolhas sociais, nas quais o sujeito é emissor e receptor de informações tendenciosas que o cercam de opiniões que ele mesmo concorda, tornando as trocas mediadas por algoritmos um eterno retorno ao ponto inicial. Tal fato prejudica a convergência proposta por Jenkins, já que apenas fragmentos de mídias selecionadas são abstraídas pelo sujeito, que não cria um senso crítico, apenas endossa a mitologia pessoal já presente e transforma em narrativa os atalhos entre um fato e outro. 


\section{Linguagens - Revista de Letras, Artes e Comunicação - ISSN 1981- 9943 \\ Blumenau, v. 14, n. 1, p. 025-044, jan./abr. 2020. \\ DOI: http://dx.doi.org/10.7867/1981-9943.2020v14n1p025-044}

Este fenômeno pode ser visto em todas as redes sociais, mas é ainda mais intenso no WhatsApp por ter desempenhado papel fundamental na estratégia eleitoral da campanha "Brasil Acima de Tudo, Deus Acima de Todos". Por meio de grupos fechados que abarcavam sujeitos já pré-dispostos a receber as mensagens em prol do presidenciável, foi criada uma grande rede de informações pós-verdadeiras.

A densidade desta amostragem pode ser delimitada em dois grupos. Um dentro da bolha social da extrema-direita, que por meio das mensagens nutria sua fidelidade a Jair Bolsonaro, cujos discursos corroboravam uma identidade moral a partir de narrativas éticas que ligavam todas as pessoas dessa bolha, tal qual o resgate dos valores tradicionais de um modelo único de família (branca, elitizada, cristã, heteronormatizante, capitalista, armada e piramidal), contrariando as pluralidades sociais contemporâneas. Já o outro grupo era composto por sujeitos que buscavam um líder que não estava envolto nos casos de corrupção enfrentados pelos presidentes anteriores, como citado por Tesich (1992) um anseio por mudanças, porém desmedido, não reconhecendo ou legitimando todos os ideais do candidato.

Nota-se aqui que a estratégia de relação social de bonding proposta por Bosco (2017) encontra efeito emancipatório, criando laços com novos grupos que possuem ideais convenientes no momento, neste caso a eleição do candidato a presidente. Assim as bolhas sociais não são desfeitas, mas avolumadas no que pode ser chamado de epidemia das bolhas. Esse efeito surge, sobretudo, nos canais digitais, onde os discursos antes proferidos apenas no ambiente fechado são emancipados, impactando mais indivíduos e manipulando a verdade.

Os 57.797 .847 milhões de votos $(55,13 \%$ dos votos totais) alcançados por Bolsonaro representam, além da vitória no pleito, o êxito nas estratégias comunicacionais. Pesquisas do Instituto Datafolha, antes do segundo turno, informavam que metade das pessoas entrevistadas acreditavam nas mensagens recebidas via aplicativos.

De acordo com a pesquisadora Mariana Valente do Instituto Internetlab (2018, s/p), o WhatsApp foi o "grande diferencial" do processo eleitoral, com papel proeminente no período próximo da votação. Valente (2018) cita também que na campanha de Jair Bolsonaro houve uma articulação de redes multiplataformas construídas desde 2013, envolvendo redes sociais como Facebook e YouTube, mas com foco no WhatsApp.

Após tais contextualizações, sentencia-se o grande propósito ao se estudar a pósverdade: analisar a comunicação social contemporânea e seus efeitos reais ao convívio social e à participação democrática. Este artigo, ao realizar o estudo do caso, não tem como objetivo principal entender a complexidade das estratégias de marketing político utilizadas, mas sim 


\section{Linguagens - Revista de Letras, Artes e Comunicação - ISSN 1981- 9943 \\ Blumenau, v. 14, n. 1, p. 025-044, jan./abr. 2020. \\ DOI: http://dx.doi.org/10.7867/1981-9943.2020v14n1p025-044}

criar um percurso que identifique a utilização das novas verdades dentro dos contextos eleitorais e digitais.

As múltiplas formas discursivas que moldam o conceito da verdade alteram a percepção social das narrativas e da identidade, e exemplificar a linha tênue entre a comunicação social factual e a livre construção de narrativas a partir de um case eleitoral sul-americano pode auxiliar na composição de um panorama global desse novo cenário que já é notado tanto na América do Norte, no caso da eleição americana de Donald Trump (2016), quanto em território europeu, no referendo Brexit no mesmo ano.

\subsection{CONSTRUINDO VERDADES}

Após analisar fatos históricos e atuais que ajudaram a sedimentar a presença da pósverdade, além de identificar cases contemporâneos da utilização de tais discursos, como a campanha "Brasil Acima de Tudo, Deus Acima de Todos", chegou-se ao campo que tange a comunicação social e um novo espaço público. Neste cenário discursos pós-verdadeiros passam a ser construídos, como os casos já citados de que não houve ditadura no Brasil, conteúdos eróticos são distribuídos em escolas e o Kit Gay. Esses fatos de maneira reduzida podem apresentar uma verdade pessoal, porém, representam grande risco ao viés democrático de um Estado.

No estudo de caso realizado, notou-se que o presidenciável Jair Bolsonaro utilizou na disputa eleitoral discursos pós-verdadeiros, que atingiram alcance maior ao serem reproduzidos via WhatsApp. Entretanto, deve-se salientar que seria generalista direcionar somente a um único sujeito toda a raiz deste fenômeno no Brasil, visto que demais figuras políticas usufruíram dos mesmos artifícios.

Recorre-se novamente ao teórico Henry Jenkins, que em 2014 - em obra conjunta com Joshua Green e Sam Ford - cunha o termo cultura da conexão. Na obra, o autor aprofunda as temáticas da cultura da convergência, pontuando que nessa nova abordagem:

\footnotetext{
Não se supõe que as novas plataformas liberem as pessoas de velhas limitações, mas, em vez disso, sugere que as facilitações da mídia digital funcionam como catalisadoras para a reconceituação de outros aspectos da cultura, exigindo que sejam repensadas as relações sociais, que imaginemos de outro modo a participação cultural e política e que se reconfigure as estruturas legais (FORD; GREEN; JENKINS, 2014, p. 26).
} 


\section{Linguagens - Revista de Letras, Artes e Comunicação - ISSN 1981- 9943 \\ Blumenau, v. 14, n. 1, p. 025-044, jan./abr. 2020. \\ DOI: http://dx.doi.org/10.7867/1981-9943.2020v14n1p025-044}

Percebe-se que a cultura da conexão ajuda a sintetizar a pós-verdade na sociedade contemporânea, compreendendo que a construção desta advém do processamento de informações de cada sujeito. Cabe assim às novas plataformas digitais criarem ambientes mais democráticos e que privilegiem o viés verdadeiro.

Fatos recentes publicados em veículos de comunicação ratificam tal posição, como as manifestações no Reino Unido em março de 2019 para a não saída do país da União Europeia - negando a votação do Brexit. Os mais de 500 mil manifestantes pontuavam que haviam sidos enganados de diversas maneiras e que votaram no referendo sem entender o verdadeiro preço a pagar ao sair do bloco econômico. Esse efeito que pode ser entendido como arrependimento, trata-se de uma imersão para uma leitura crítica dos fatos, onde os acontecimentos são analisados não apenas dentro da bolha social; sentenciando a pós-verdade como algo não condizente com a realidade, mas sim como discursos de carga emocional e pessoal, prejudiciais à democracia.

No mesmo viés de reconhecimento da interferência da pós-verdade em eventos políticos e emancipados via redes sociais, o WhatsApp criou uma plataforma local na Índia chamada Checkpoint Tipline, que é um canal dentro do próprio aplicativo para denunciar e checar notícias falsas enviadas durante o pleito eleitoral de 2019. Além de buscar a idoneidade da eleição vigente, a ação representa grande importância ao criar uma base para futuras pesquisas que objetivam entender o poder de influência das novas redes na criação de verdades.

Nota-se que mesmo em um ambiente constituído por inúmeras novidades, pode-se afirmar que o case "Brasil Acima de Tudo, Deus Acima de Todos", aqui analisado, é parte formadora do novo cenário social brasileiro, que com o apoio da internet e plataformas como o WhatsApp criaram inúmeras verdades que foram compartilhas em bolhas sociais específicas, ajudando a reproduzir no Brasil fato visto em escala global recentemente, capaz de alterar a forma que a comunicação social é encarada, colocando-a em ainda maior grau de importância nos estudos da atualidade ao reconhecer a pós-verdade como um grande fenômeno moldado pela contemporaneidade e influenciador de importantes acontecimentos.

\section{CONCLUSÃO}

No século XXI, o acesso às informações foi facilitado por uma nova forma de comunicação, a internet, que criou um novo espaço público. Este cenário apresenta um centro informacional decentralizado, relegando o poder das mídias tradicionais e possibilitando a 


\section{Linguagens - Revista de Letras, Artes e Comunicação - ISSN 1981- 9943 \\ Blumenau, v. 14, n. 1, p. 025-044, jan./abr. 2020. \\ DOI: http://dx.doi.org/10.7867/1981-9943.2020v14n1p025-044}

construção de diversas narrativas simultâneas. Porém, muitas vezes essas histórias são contadas de forma superficial, devido à presença dos algoritmos nas redes sociais. Eles privilegiam a visualização de publicações semelhantes ao que os usuários tenham interagido anteriormente, recebendo informações conformistas, não estimulando o senso crítico.

O fortalecimento desse fato intensifica a criação das bolhas sociais nas sociedades contemporâneas. Esses grupos se caracterizam por serem ambientes fechados e compostos por indivíduos com ideais semelhantes. Dentro das bolhas são emitidos discursos que convém a todos por representar o conjunto ético-moral dos presentes, excluindo-se em diferentes cenários a importância dos fatos constituintes da realidade. Um novo ambiente discursivo é criado, no qual, com o fortalecimento das verdades subjetivas, é possível teorizar a pós-verdade.

Neste momento, as verdades adquirem outra conjuntura, onde a realidade passa a segundo plano, enquanto o "como" se conta a história ganha importância e se sobrepõe ao "o quê" se conta. Não se trata mais de saber o que ocorreu, mas de escutar, assistir, interpretar versões de fatos a partir da ótica das ideologias próprias (LLORENTE, 2017, p. 9). Em face da contextualização, nota-se a influência que a pós-verdades exerce sobre os acontecimentos sociais, visto a forma com que os discursos públicos são recebidos.

Confirma-se essa influência ao comprovar o poder de persuasão dos discursos pósverdadeiros nas campanhas de Donald Trump (2016) e do referendo Brexit (2016), além de verificar seu uso, como ferramenta de marketing político, na campanha de Jair Bolsonaro (2018). O case das eleições presidenciais brasileiras conduziu a presente pesquisa, utilizandose da coleta de dados bibliográficos e de artigos da internet, criando uma narrativa que interligava o estudo de caso com a pós-verdade e o novo espaço público, caracterizado aqui principalmente pelo WhatsApp. A relação entre as temáticas representa grande importância para a Publicidade e Propaganda, sobretudo na área da comunicação social, analisando eventos cotidianos sob uma ótica crítica, identificando as raízes das problemáticas.

Com esta abordagem crítica social, o objetivo geral de pesquisa - interpretar o contexto de pós-verdade, relacionando com os discursos emitidos via WhatsApp ligados à campanha "Brasil Acima de Tudo, Deus Acima de Todos" no último período eleitoral brasileiro - foi atendido. Com um percurso iniciado na conceituação das várias narrativas da verdade que culminaram na pós-verdade, verificou-se também o importante status ocupado pela internet atualmente, para por fim compreender o case.

Com ciência do objetivo geral, sentencia-se que a resposta para se "a pós-verdade pode explicar a crença na imensidão de boatos espalhados via WhatsApp no último período eleitoral 
brasileiro?" é de que apenas em partes a pós-verdade pode esclarecer tal fenômeno. Pois, em muitos fatores pode se comprovar a presença de discursos pós-verdadeiros nas mensagens emitidas via aplicativo, além de entender o ambiente sociopolítico com terreno rico em narrativas de apelo emocional. Porém, afirmar que unicamente a pós-verdade explica este novo cenário é reducionista, outros estudos sociais devem ser realizados para compreender o poder do WhatsApp e também um aprofundamento no que tange o marketing político em torno da campanha "Brasil Acima de Tudo, Deus Acima de Todos".

A atualidade da temática da pós-verdade, faz crer que as verdades universais foram abandonadas e a ideia de objetividade é rejeitada quando conveniente. Argumentos lógicos e discursivos caem no vazio, são substituídos por frases curtas e efetivas com imagens sugestivas, novas fórmulas que estimulam o emocional, apontando para o medo e a ironia (ANGELIS, 2017, p. 37). Tal conceituação vislumbra que apoiada no poder das novas mídias, o fenômeno tende a manter grande impacto.

Esta interferência será estudada de forma ainda mais desenvolvida nos próximos anos no âmbito da comunicação, não mais apenas para identificar sua causa e efeito, porém principalmente objetivando minimizar suas adversidades perante os acontecimentos sociais, alertando os indivíduos da importância do senso crítico e do debate de ideias opostas, formando uma sociedade democrática.

\section{REFERÊNCIAS}

AGÊNCIA BRASIL. Notícias falsas influenciaram eleições deste ano, dizem pesquisadores. Disponível em: https://is.gd/KnVROa. Acesso em 18 de mai de 2020.

AGÊNCIA LUPA. A primeira agência de fact-checking do Brasil. Disponível em: https://is.gd/ocLL3V. Acesso em 14 de mai de 2020.

BEZERRA, A.C; CAPURRO, R; SCHNEIDER, M.Regimes de verdade e poder:dos tempos modernos à era digital. Revista Liinc, v. 13, 2017.

BOSCO, F. A vítima tem sempre razão? São Paulo: Todavia, 1ª ed., 2017.

CAOS FILOSÓFICO. Com a pós-verdade, contrapor é cansativo. Disponível em: https://is.gd/alEkhf. Acesso em 06 de nov. de 2019.

D'ANCONA. M. Pós-verdade a nova guerra contra os fatos em tempos de fake News. Barueri: Faro Editorial, $1^{\mathrm{a}} \mathrm{ed}$., 2018.

EL PAÍS. Caso Cambridge Analytica. Disponível em: https://is.gd/qb4Kqj. Acesso em: 24 de mar. de 2019. 
EL PAÍS. Dicionário Oxford dedica sua palavra do ano, 'pós-verdade', a Trump e Brexit. Disponível em: https://is.gd/aKPWrP. Acesso em: 24 de fev. de 2019.

FORD, S; GREEN, J; JENKINS, H. A Cultura da Conexão: criando valor por meio da mídia propagável. Trad. Patrícia Arnaud - São Paulo: Aleph, 2014.

G1. Manifestação em Londres pede segundo referendo sobre o Brexit. Disponível em: https://is.gd/f2wlyd. Acesso em: 14 de abr. de 2019.

GILLESPIE, T. A relevância dos algoritmos. Revista Parágrafo. São Paulo, brasil, v.6.

HIGA, P. Estes são os 15 apps mais usados pelos brasileiros. Disponível em: https://is.gd/Ow4eXc. Acesso em 30 de mar., de 2019.

JENKINS, H. Cultura de Convergência. Trad. Suzana Alexandria. - 2. ed. - São Paulo: Aleph, 2009.

LLORENTE, A. A era da pós-verdade: realidade versus percepção. Revista UNO. São Paulo, v 27, 2017.

MÉTODOS e técnicas de pesquisa em comunicação. 2. ed. São Paulo: Atlas, 2011.

O GLOBO. Bolsonaro é descrito como 'Trump dos trópicos' e 'fervoroso admirador de Trump' na imprensa internacional. Disponível em: https://is.gd/DNDI67. Acesso em: 22 de mar. de 2019.

OXFORD DICTONARIES. Word of the year 2016 is. Disponível em: https://is.gd/JFxYlg. Acesso em: 22 de fev. de 2019.

PARISER, Eli. O filtro invisível: o que a internet está escondendo de você. Rio de Janeiro: Zahar, 2012.

PROJETO COMPROVA. Jornalismo colaborativo contra a desinformação. Disponível em: https://is.gd/Ak6syH. Acesso em 14 de mai de 2020.

REDE MÍDIA. Pós Verdade- Rede Mídia. 2017. Disponível em: https://is.gd/kb9rLZ. Acesso em: 19 de mar. de 2019.

REUTERS. WhatsApp lança serviço de checagem de fatos durante eleições na Índia. Disponível em: https://is.gd/UiOJFC. Acesso em 12 de abr. de 2019.

RIGA, M; BEGATINI, O. Disseminado pelo Brasil, WhatsApp deve ser canal decisivo nas eleições. Disponível em: https://is.gd/QE83kf. Acesso em 25 de mar., de 2019.

UM BRASIL. Pós-verdade na era da informação, por Alexis Wichowski. 2017.

Disponível em: https://is.gd/1Ec8m2. Acesso em: 19 de mar. de 2019. 